\title{
Students' Perception and Practice of Writing through Peer-led Learning (PLL) at Bahir Dar University
}

\author{
Abiy Yigzaw* \\ Department of English, Faculty of Humanities, Bahir Dar University, Bahir Dar, Ethiopia
}

\begin{abstract}
This study endeavored to probe into Bahir Dar University (BDU) English majoring students' perceptions and practice of learning writing through 'one-to-five' peer-led organization (called PLTL at BDU). The number of English major students at BDU in the 2013/14 Academic Year was only 19 , and all were included in the study. Data were gathered through questionnaire and interview and were analyzed comparing obtained mean against determined expected mean, rank order and narration of the interview responses. The results of the study indicated that participants favored the fixed 'one-to-five' peer-led grouping, and witnessed its significance in learning writing. They also esteemed that the tasks and materials they used for practicing writing during peer discussion were of great help to their classroom learning. However, they said that teacher's support and commitment, peer leaders' assistance and commitment as well as peer members' zeal and participation was negligible. It was also found that participants favored teacher-guided learning, tutor-guided learning, collaborative learning through varying groups, individual-based learning, and collaborative learning in fixed groups in that order. The interviewees had also unveiled that teacher's support and peer-leaders' capacity and commitment as well as group members' commitment was far below the expected. Group members also tended to depend on one or two students for all tasks given to groups. Hence, they thought that PLTL had not achieved the objective it was sought to get done. Finally, it was concluded that though students' favored the fixed, 'one-to-five' peer-led organization in learning writing, they practically prioritized teacher-guided learning probably because of the drawbacks they observed, as they reported it in the interview, in the practical implementation of the system. So, it was recommended that teachers, peer leaders and group members should devotedly engage in the system for its effectiveness. It was also recommended that BDU should devise a strategy and guideline that could strictly be followed by the different parties to get the maximum benefit from PLTL; that is, the 'one-to-five' group discussion to enhance students' writing ability.
\end{abstract}

Article Information

Copyright@2015 STAR Journal, Wollega University. All Rights Reserved.

\section{Article History:}

Received : 12-02-2015

Revised : 23-03-2015

Accepted : 26-03-2015

Keywords:

PLTL

Fixed

One-to-five

Peer groups

Peer-led learning

${ }^{*}$ Corresponding Author:

Abiy Yigzaw

E-mail:

abiyyigzaw@yahoo.com

\section{INTRODUCTION}

Currently, Ethiopian schools of different levels have stimulated a fixed 'one-to five' group structure. The 'oneto-five' structure (grouping system) comprises of six students, one of whom is the best achiever and the leader of the group. The leader continues his/her leadership unless anyone of the group members outsmarts him/ her in semester examinations. The rest of the group members are mixed ability students and gender representatives. The 'one-to-five' peer-led learning structure is a one-off and permanent organization in which students who belong to a group collaboratively perform tasks of different subjects both in class and outside.

Bahir Dar University (BDU) has plumped for and endeavored to institutionalize peer-led team learning and named it as Peer-Led Teaching Learning (PLTL). The University allegedly reported that an awareness creation program was organized for officials at the different ladder in the hierarchy to develop purpose clarity, motivation and reciprocated understanding. In the peer-led team learning initiative, the team was organized on the basis of mixed ability groups which may alter every semester down to the change of individual members' academic performance. The size of the group was suggested to be six, one of whom would be the best performer and leader and the rest to incorporate diversity in age, sex, academic performance, language, ethnicity, religion, etc. to provide them with an opportunity to intercultural interaction and integrity. The various duties of peer leaders, classroom teachers and course chairs are indicated very briefly below.

Team leaders play a facilitative role in egging on members to prompt questions, become responsible for their own learning, develop innovativeness, and have the skill for problem-solving and reflection. Team leaders are also required to create forums, which will be mentored by teachers, to share experiences both in academic content and leadership. The mentor has the duty of monitoring, 
evaluating and supporting a section via direct and regular contact with team leaders.

The mentor checks teams' engagement in peer learning, facilitates new election of leaders when the need arises, reports about the status of peer learning to responsibilities, motivates peer leaders and enables them to become effective and efficient leaders. The classroom teachers, on the other hand, provide students with intellectual scaffolding, engage them in learning activities and work collaboratively with mentors and course chairs. The course chairs specifically play managerial roles in giving directions and feedback, evaluating the instructional strategy, and responding to issues that need special attention together with other responsibilities (BDU, Peer Learning Guideline).

This study endeavors to find out BDU English major students' perception and practice of PLL in learning writing. Since PLL is only recently begun in its present structure in the University, the researcher believes that it is timely to study the issue for better implementation. Writing is focused because it is considered by many as 'an individual activity' (Pugazhenthi, 2013:828) though there are evidences that it can also be more fruitful when accomplished collaboratively (e.g. Johnson and Johnson, 1998). Therefore, this study attempts to respond to the following questions.

1. How do students perceive and practice learning writing through PLL?

2. How do participants rank the different group structures and other learning modes?

\section{The concept of peer-led learning}

Peer-led learning (PLL), performed by a more capable student as the overseer of a small group of learners, aims at reducing students' anxiety and building confidence. It is a 'pedagogy of engagement' intended for enhancing students' understanding of content, enriching skills, reducing retention and improving passing rates. For the success of PLL, peer leaders play a paramount role as role models for their low-achieving peers in planning, modeling, managing and implementing content (learning objectives) (Flores et al, 2010).

Built on the constructivists' and involvement philosophies (theories), PLL maintains the principle that students learn actively through 'individual and social processes" in the form of mediated peer-to-peer learning. In this principle, social processes mediate students' personal knowledge by providing interactive, active and collaborative learning environment. Students discuss, debate, and solve problems collaboratively. As Tien, Roth and Kampmeier (2002:209) stated, "Through the interpersonal interactions as students work together solving problems, ideas are shared, evaluated, and refined, and each individual translates the experience into robust, useable knowledge." Peer discussion is relevant for "sharing, clarifying, and distributing knowledge among peers" (Rivard \& Straw, 2000: 585). The discussion leads to and improves students' reasoning (Hogan, Nastasi \& Pressley, 2000). It is also considered as relevant for sharing of ideas among students and, as a result, constructing personal meaning, and filling in missing background information (Berne \& Clark, 2006). Students get opportunity to produce high quality and quantity of language if teachers do not dominate their shares (ibid.).
PLL, as an instructional practice, is consistent with socio-cultural models of learning (Berne \& Clark, 2006) and response-based theories of comprehension (ibid.). PLL helps students to engage in and become creative in learning. In PLL, the support peers get is bi-directional; that is, the individual supports the group, and the group supports the individual. The interplay between the personal and group knowledge, strategy and skills sharing helps students to escalate their learning- developing it from surface to deep learning.

In PLL, students support each other in areas which are within their zone of proximal development (ZPD). Betterperforming students scaffold the integrity and autonomy of the less able ones while learning conceptually rich materials. Previously, scaffolding was assumed to be feasible asymmetrically between teachers and students, parents and children and similar other relations. Currently, however, peer scaffolding is also deemed to apply symmetrically between peers (Fernández et al., 2001). Peer scaffolding was also recommended by social constructivists who noted its relationship with ZPD. For instance, Vygotsky (1978; as cited by Fernández et al, 2001:42) described ZPD as:

The distance between the actual developmental level as determined by independent problem solving and the level of potential problem solving as determined through problem solving under adult guidance or in collaboration with more able peers.

In the above description of ZPD, Vygotsky indicated both the asymmetrical and symmetrical relations between the mediator and the mediatee (the supporter and the scaffold). PLL helps students develop cooperative learning, integrate positive interdependence and face-toface interaction. This study emphasizes peer-to-peer support in solving learning problems, improving their capacity and becoming reflectors and deeper learners. To be effective, PLL incorporates organizational arrangements, peer leadership, use of mediocre challenging materials and integration of materials with learning materials.

Briefly put, PLL is implemented to enhance learning through students' engagement. Students and their peer leaders involve in learning, and their learning improves. Engagement in learning helps students to develop "confidence and perseverance," and to foster "a variety of presentation and team-related skills" (Bunce, 2007:535). PLL is led by group leaders who serve as role models; therefore, they are expected to demonstrate higher academic performance, and communication and leadership skills. They also serve as a bridge between students and instructors.

\section{Learning Writing through 'One-To-Five' Peer-Led Structure}

Flores et al (2010) have noted that peers have gained both managerial and deep learning capabilities in their peer-led learning. Similarly, Curran et al (2013) asserted that students in the peer-led program acquired greater content mastery compared to those who did not involve. The experience has also equipped students with positive attitudes and perceptions about PLL. Research has also shown that PLL improves students' performance, retention, and attitudes about their lessons (Tien, Roth \& Kampmeier, 2002). The authors have also asserted that 
the social constructivist foundation of the peer-led learning has been a workable mechanism for effecting change in students' thinking. Bunce (2007), on the other hand, reported that PLL is characterized by greater involvement and engagement. Berne and Clark (2006) suggested that in PLL students should share learning strategies and become responsible for their own learning as well as their group learning. PLL is applied at BDU in teaching writing and other courses in English as well as other disciplines for purposes stated by different scholars above.

\section{MATERIALS AND METHODS}

\section{Participants of the Study}

The participants of the study were 19 first year English major students at Bahir Dar University who took writing course. Of the 19 students 16 were female and 3 were male. All the students were taken as sample for the number was manageable. All the 19 responded to the questionnaire, and four of them participated in the interview. The interviewees (three female and one male) were selected randomly using lottery system.

\section{Instruments Used}

Questionnaire and interview were employed as data collection instruments. The questionnaire had two parts; and the first part constituted 35 items which were categorized in 6 groups. The first group which consisted of 8 items required information about peer-led grouping; whether or not the small (a group of six), fixed (permanent) and mixed grouping of peer-led groups was a good way; while the second category which constituted 15 items revolved around the benefits of learning writing in peer-groups. The three items in the third category sought information whether or not the materials they used for discussion had a direct relevance to the classroom writing lessons. The two items in the fourth category inquired the extent of the peer-groups in the provision of opportunities of engagement in discussions to participants. The three items in the fifth and the four items in the sixth categories wanted information about the adequacy of support students receive from instructors and peer leaders. These items were developed in a five point Lickert Scale that ranged from 'Strongly Agree' to 'Strongly Disagree', which were given values that ranged from 5 to 1 . The items were developed by the researcher based on the literature he has read, and for validity, the Quality Assurance Director of Bahir Dar University and two other professors in the University commented on the items against the research questions.

In the second part of the questionnaire which comprised five items, the participants of the study were required to rank the items in order of importance to learn writing best. The contents of the items were collaborative learning through varying the group members, using fixed group members, the relevance of tutor-guided learning, individual-based and teacher-guided learning writing.

\section{Interview}

The interviewees were asked about their perceptions regarding the actual peer-led learning program they were involved in, their beliefs about its advantages, the actual benefits they acquired, their preference of peer-group learning compared with teacher lecture, the challenges they faced, and their recommendations about what should be done for learning writing better in peer-groups. The interviews were conducted in a classroom by a colleague who currently studies for his PhD in Teaching English as a Foreign Language (TEFL).

\section{Methods of Data Analyses}

The participants' responses to the questionnaire were analysed comparing obtained mean values for the categories against the expected means of the categories to determine the group behaviour. Accordingly, the expected means for fixed grouping, significance, materials used, student participation, instructor guidance and peer leader's support were $24,45,9,6,15$ and 12, respectively.

Besides, rank order of the selected variables was made. Accordingly, the items incorporated in the questionnaire were ranked and analysed using the sum of the participants' responses for each item; while the responses obtained from the interview were described.

\section{RESULTS}

As stated above, this study required information about whether or not students favoured fixed grouping and the significance of peer-led learning in improving writing. Besides, it inquired about whether or not the materials students use in their peer group discussion add value as support materials to what they study in writing classes, and, as a result, enhance their writing ability. In order to see the group's behaviour in this regard, the computed means of the variables were compared against the expected means. Accordingly, the results indicated that the participants favored the fixed grouping, were aware of the significance of learning writing through 'one-to-five groups', and witnessed that the materials they used in groups for discussion were of good supplement for them to enhance their writing ability. As shown in Table 1, the mean of fixed grouping $(M=28.32 ; S D=4.36)$ exceeded the expected mean of 24 of the fixed group category. Similarly, the mean of students' perception about the significance of peer-led learning writing $(M=50.26$; $S D=10.03$ ) was greater than the expected mean of 45 . Therefore, the results suggest that students perceived that peer-led learning could significantly contribute to their development of writing in English. However, the expected means of student participation (5.11; $S D=2.66)$, instructor's guidance $(M=9.84 ; S D=2.61)$ and the role played by the peer leader $(M=11.58 ; S D=2.85)$ were less than the expected means 6,15 , and 12 , respectively.

Table 1: One sample t-test results of students' opinions about peer-led learning

\begin{tabular}{lcccc}
\hline \multicolumn{1}{c}{ Variable } & N & Mean & Std. Deviation & Expected mean \\
\hline Fixed grouping & 19 & 28.3158 & 4.35957 & 24 \\
Significance & 19 & 50.2632 & 10.03240 & 45 \\
Materials used & 19 & 10.1579 & 2.21769 & 9 \\
Student participation & 19 & 5.1053 & 2.66447 & 6 \\
Instructor's guidance & 19 & 9.8421 & 2.60903 & 15 \\
Peer leader's support & 19 & 11.5789 & 2.85415 & 12 \\
\hline
\end{tabular}


Participants were asked to rank their preferences among varying or fixed collaborative groups, tutor-guided, individual or teacher-guided learning writing. Their responses are summarized in Table 2. The participants favoured teacher-guided learning writing most, followed by tutor-guided learning. Their third preference was learning writing through collaborative groups whose members change in different tasks. They ranked individual-based learning as the fourth preference, while they favoured collaborative learning in fixed groups the least. This finding seems contradictory to the responses given by the interviewees as reported below.

Table 2: Students' ranking of learning writing through different ways

\begin{tabular}{|c|c|c|c|c|c|c|c|c|}
\hline \multirow{2}{*}{ Variable } & \multirow[b]{2}{*}{$\mathbf{N}$} & \multicolumn{5}{|c|}{ Scales } & \multirow{2}{*}{$\Sigma$} & \multirow[b]{2}{*}{ Rank } \\
\hline & & 1 & 2 & 3 & 4 & 5 & & \\
\hline Collaborative learning in varying groups & 19 & 1 & 4 & 7 & 2 & 5 & 63.00 & 3 \\
\hline Tutor-guided learning & 19 & 2 & 3 & 6 & 8 & - & 58.00 & 2 \\
\hline Collaborative learning in fixed groups & 19 & 1 & 4 & 4 & 5 & 5 & 66.00 & 5 \\
\hline Individual-based learning & 19 & 3 & 5 & 1 & 2 & 8 & 64.00 & 4 \\
\hline Teacher-guided learning & 19 & 12 & 3 & 1 & 2 & 1 & 34.00 & 1 \\
\hline
\end{tabular}

In addition to the results obtained through questionnaire, data was gathered using interviews. The interview questions inquired about the interviewees' perceptions about the peer-led learning program, their beliefs about its advantages, and the actual benefits they acquired. Besides, the questions required information about whether or not the interviewees prefer peer-led learning to teacher's lecture, the challenges they faced while implementing the peer-led learning program, and their opinions about what should be done in future for better implementation of the program. Accordingly, the following results were obtained.

All the four interviewees believe that the peer-led learning program is vitally important for bringing quality education. Three of them, however, had doubts on its practicality for they have observed lack of commitment among students, and dependence on the group leader or other better performing group members.

Apropos of the advantages students may secure from peer-led learning, one of the interviewees responded that it is expedient for students to ask for clarity and explication unreservedly, share ideas, and discuss among peers without apprehension- value that students lack in teacher-fronted classes. In teacher-fronted classes, the majority of the students are reticent being wary of making mistakes. The other interviewee, appreciating the participatory role the program endows students with, had a resentment that teachers' support had dwindled levying the burden on students in the peer-groups. The third interviewee also had a positive standpoint about the importance of peer-led learning; however, she had mentioned the students' dependence on other betterperforming students, particularly the group-leaders, as an evidence of failure in the actual practice. The fourth interviewee stated that peer-led learning is beneficial in providing opportunity for knowledge (experience) sharing among peers, improving students' achievement, enhancing students' engagement in academic activities, alleviating learning problems, developing social interdependence and respect among students, and using time economically.

In response to their choice between teacher-fronted and peer-led learning writing, the interviewees had varied views. One of the interviewees said that teacher's lecturing and students' discussion complement to each other (they are two sides of a coin), while the second interviewee argued that teacher's lecture is more important. According to the first interviewee, the teacher lectures on a certain issue which students develop and understand in depth in their groups assisting each other; but the second interviewee retorts that the teacher should do the job for writing is a difficult task to students to support their peers. The third interviewee had also favored teacher's lecture. Her reason for this was the low trust she had to her peers about their knowledge of the subject matter though it was easy to discuss with them. The fourth interviewee, on the other hand, preferred learning from her peers to learning from her teacher since she could ask her peers about her doubts more freely than she could ask her teacher.

The challenges the students encountered during peerled learning comprised of disrespect among peers, procrastination and cancelling of already arranged programs by group leaders, and some students look their peers contemptuously when they fail to respond to questions or participate in the group. In addition, some students are careless, group organization is awry (in many cases better students are grouped together), and teachers burden students with too many tasks. Other problems include disagreement stirred up among students, lack of responsibility and levying the entire burden to group leaders, and less attention given by students and teachers to peer-led learning.

The interviewees have recommended teachers' followup as a crucial role for positive effects of peer-led writing. They also said that a guideline should be established to make the program participatory, and, above all, teachers' and students' attitudes towards peer-led learning should be changed.

\section{DISCUSSION}

The different instruments employed in this study seem to superficially disclose a discrepancy between the findings. The comparison between means of variables and expected means divulged that the participants of the study favored fixed grouping (the 'one-to-five' grouping) in learning writing, positively valued learning writing through peer-led discussions, and presumed that the materials they used in their peer discussion could significantly support their classroom writing. As Rivard and Straw (2000) and Berne and Clark (2006) stated in the literature, the participants of this study had, in principle, thought that PLL is a reasonable group structure that could pave the way to interpersonal interactions, sharing of ideas and, as a result, to construct their own meanings. Although the participants of the study assumed that peer-led learning could improve and reinforce their writing ability, and 
develop confidence and perseverance (Bunce, 2007), it did not prove these qualities practically among the peer groups in this study.

The participants have indicated that the tasks and materials used in their peer discussions were significantly important to their writing course. Contrary to the literature, participants' engagement in group tasks, instructor's guidance and support to students and peer leaders' support and devotion were less than the expected means set. As Bunce (2007:535) averred, 'peer leaders serve as role models.' They are assumed to be motivated to their peer groups which thrive beyond the life of a course. Besides, the leader serves as a bridge between students and instructors (ibid). However, these roles of the peer leaders were not reflected in this study: they rather showed laxity and indifference. Similarly, participants' reports revealed that teachers also had negligible contribution to the effectiveness of the peer-led learning. Unless teachers and peer leaders provide careful guidance to peer group members (one-to-five or PLL groups), they may discourage learning socially among peers (Bunce, 2007). In this case, learning writing through peer-led system may not help students reap significant benefits from their peers.

The order of participants' preference of group structures (collaborative learning in fixed or varying group members, and tutor-guided learning) and other modes (individual-based and teacher-guided modes) was contradictory to Flores et al's (2010) findings that peer-led team learning could improve students' learning. This study exhibited that their order of preference of the variables (Table 2) did not bear witness that fixed grouping in learning writing is a priority. The interviewees also argued that teachers levy much burden (entirely leaving tasks for students to engage in peer-led discussions) upon students providing little or no support while teaching writing. This goes against the scaffolding role teachers should play while learners are engaged in group tasks.

The placement of teacher-centered approach in first place and fixed grouping the last might have emanated from this experience of less teacher support during students' engagement in the group tasks. In other words, the controversy is, teachers' reluctance in rendering support to students might have impacted on the 'one-tofive' grouping structure to opt teacher-centered approach to writing. It might have also stemmed from students' thought that teachers play a fundamental role particularly in their learning of writing (Pugazhenthi, 2013). The other possible cause may be the belief that sprouts out from their experiences of learning writing much on teacher guidance. Teaching-based approach of teachers develops dependency on them; and therefore students could be characterized by dearth of self-efficacy and evasion of self-regulated learning. They might develop less trust in peer mediators and peer learning in general. Thus, though the participants of this study have a strong belief that the fixed peer learning structure ('one-to-five' or PLL) is very important for reasons they have indicated in their responses to the interview (e.g. freely expressing ideas, learning from peers, asking for clarification and understanding, etc.), they still want their teachers much to give them guidance about writing and correct their writings. Some students require a constant supervision of the teacher considering him/her as a figure of authority who should be always there to instruct, guide and support them. Some others have strong aversion to collectivism and preference for individualism (Robertson, 2005).

Concerning fixed grouping, students have shown a positive attitude towards it; however, they preferred it less than they did with groups with varying members. A couple of reasons might have influenced this. The first could be their past experiences of being grouped in the classroom, while the second could be their beliefs about the dynamics of grouping and group activities.

\section{CONCLUSIONS}

Participants favor the fixed 'one-to-five' grouping and witness its significance in learning writing. They also approvingly expressed that the tasks they did and the materials they used in groups were good ones. Despite these qualities fixed 'one-to-five' group discussion had, peer members' tended to depend on peer leaders and better-performing students and lacked commitment to engage in writing tasks. Besides, teacher's support and commitment as well as peer leaders' commitment and capacity were trifling. Therefore, peer groups opted to have teacher-led writing classes rather than PLL. Based on the findings, it is recommended that teachers, peer leaders and peer group members should enthusiastically engage in the system for its effectiveness. It is also recommended that a strategy and guideline be devised that could be adhered to to obtain maximum benefit from PLL; that is, the fixed 'one-to-five' group discussion to enhance students' writing.

\section{Conflict of Interest}

Author declared no conflict of interest regarding publishing this paper.

\section{REFERENCES}

BDU, Peer-led Team Learning Implementation Guideline (Unpublished).

Berne, J.I. and Clark, F.C. (2006). Comprehension strategy use during peer-led discussions of text: Ninth graders tackle "The Lottery". Journal of adolescent and adult literacy 49(8): 674-686.

Bunce, D.A. (2007). Evaluating Peer-Led Team Learning: A Study of Long-Term Effects on Former Workshop Peer Leaders. Journal of Chemical Education 84(3): S35-539.

Curran, E.M., Kerri Carlson., Dayius L. Turvold Celotta (2013). Changing attitudes and facilitating understanding in the undergraduate statistics classroom: A collaborative learning approach. Journal of the Scholarship of Teaching and Learning 13(2): 49-71.

Fernández, M., Rupert Wegerif., Neil Mercer and Sylvia Rojas-Drummond. (2001). Re-conceptualizing "Scaffolding" and the Zone of Proximal development in the Context of Symmetrical Collaborative Learning. Journal of Classroom Interaction 36(2): 40-54.

Flores, B., James Becvar., Ann Darnell., Helmut Knaust., Jorge Lopez., Josefina Tinajero. (2010). Implementing peer led team learning in gateway science and mathematics courses for engineering majors. American Society for Engineering Education.

Hogan, K., Nastasi, B. K. and Pressley, M. (2000). Discourse patterns and collaborative scientific reasoning in peer and teacher-guided discussions. Cognition and Instruction 17(4): $379-432$ 


\section{Abiy Yigzaw}

Johnson, D. and Johnson, R. (1998). Cooperative learning and social interdependence theory: Cooperative learning. www.co-operation.org/pages/SIT.html ${ }^{*}$

McMahon, S. and Raphael, T. (1997). The book club connection. New York: Teachers College Press.

Pugazhenthi, C.D. (2013). Writing is an individual activity. Language in India. 13(6): 827-829.

Rivard, L.P. and S.B. Straw. (2000). The effect of talk and writing on learning science: An exploratory study. Science Education 84: 566-593.

Robertson, E.J. (2005). The effects of learning styles on group development in an online learning environment.
Sci. Technol. Arts Res. J., Jan-March 2015, 4(1): 197-202

Unpublished MA Thesis, University of North Carolina Wilmington.

Rosenblatt, L.M. (1978). The reader, the text, the poem. Carbondale and Edwardsville, IL: Southern Illinois Press.

Tien, L.T., Roth, V. and Kampmeier, J.A. (2002). Implementation of a Peer-Led Team Learning Instructional Approach in an Undergraduate Organic Chemistry Course. Journal of research in science teaching 39(7): 606-632.

Vygotsky, L. (1978). Interaction between learning and development. Cambridge, MA: Harvard University Press. 